\title{
Magnetic Abrasive Flow Machine Based Super Surface Finishing
}

\author{
Prof. Saurabh A. Bobde1, Prof. Satish G. Sonwane1, Prof. Harshyu A. Bhimgade² \\ 1,2 Assistant Professor \\ ${ }^{1}$ Dr. Babasaheb Ambedkar College of Engineering and Research, Nagpur, Maharashtra, India \\ ${ }^{2}$ Rajiv Gandhi College of Engineering and Research, Nagpur, Maharashtra, India
}

How to cite this paper: Prof. Saurabh A. Bobde | Prof. Satish G. Sonwane | Prof. Harshyu A. Bhimgade "Magnetic Abrasive Flow Machine Based Super Surface Finishing" Published in International Journal of Trend in Scientific Research and Development (ijtsrd), ISSN: 24566470, Volume-3 | Issue-3, April 2019, pp.350-352, URL: http://www.ijtsrd.co $\mathrm{m} /$ papers/ijtsrd217 33.pdf

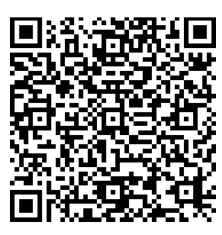
IITSRD21733

Copyright (C) 2019 by author(s) and International Journal of Trend in Scientific Research and Development Journal. This is an Open Access article distributed under the terms of the Creative Commons

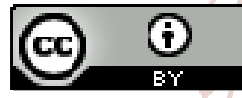
Attribution License (CC BY 4.0) (http://creativecommons.org/licenses/ by $/ 4.0$ )

\section{INTRODUCTION}

Magneto abrasive flow machining (MAFM) is a new technique in machining. These processes can be classified as hybrid machining processes (HMP) _ a recent concept in the advancement of non conventional machining. The reasons for developing a hybrid machining process is to make use of combined or mutually enhanced advantages and to avoid or reduce some of the adverse effects the constituent processes produce when they are individually applied. The present paper reports the preliminary results of an on-going research project being conducted with the aim of exploring techniques for improving material removal rate (MRR) in AFM. One such technique uses a magnetic field around the work piece during machining. Magnetic fields introduce such a machining force toward machining in magnetic abrasive finishing (MAF), used for micro machining and finishing of components, particularly circular profile.

Magneto Abrasive flow machining (MAFM) is one of the latest non-conventional machining processes, which possesses excellent capabilities for finish-machining of inaccessible regions of a component. It has been successfully employed for deburring, radiusing, and removing recast layers of precision components. High levels of surface finish and sufficiently close tolerances have been achieved for a wide range of components .In
MAFM, a semi-solid medium consisting of a polymerbased carrier and abrasives with ferromagnetic particles in a typical proportion is extruded under pressure through or across the surfaces to be machined. The abrasion takes place between surface and abrasive results in material removal in form of small chip particle which mix with slurry and work as tool. A special fixture is generally required to create restrictive passage or to direct the medium to the desired locations in the work piece. This report discusses the possible improvement in surface roughness and material removal rate by applying a magnetic field around the work piece in AFM. Relationships are developed between the material removal rate and the percentage improvement in surface roughness of steel component when finish-machined by this process.

\section{OVERVIEW}

Abrasive flow machining (AFM) is a non-traditional machining process that was developed in the USA in the 1960s. This provides improvement in surface roughness and material removal rate, polish intricate geometries. The process has found applications in a wide range of fields such as aerospace, defence, and surgical and tool manufacturing industries. Extrusion pressure, flow volume, grit size, number of cycles, media, and work piece 
configuration are the principal machining parameters that control the surface finish characteristics. Recently there has been a trend to create hybrid processes. This has opened up new vistas for finishing difficult to machine materials with complicated shapes which would have been otherwise impossible. These processes are emerging as major technological infrastructure for precision, micro, and nano scale engineering. This review provides an insight into the fundamental and applied research in the area and creates a better understanding of this finishing process, with the objective of helping in the selection of optimum machining parameters for the finishing of varied work pieces in practice. The various limitations of Abrasive Flow Machining are overcome like:

1. Low finishing rate. 2. Low MRR. 3. Bad surface texture. 4. Uneconomical.

\section{EXPERIMENTAL SETUP}

An experimental set-up is designed and fabricated as shown in fig.1. The machine has two actuators. These actuators can hydraulic or pneumatic operated with the use of synchronize circuit. Circuit contains direction control valve which is push button operated, controls the flow of pressurized fluid and result into desire motion of cylinder piston. Tooling is the vacant chamber is use to store abrasive slurry, and it is made up from nylon material as it is not affect by abrasive particles. This abrasive slurry flows from lower tooling to upper tooling and then vice versa this makes on cycle of machining. Fixture is design in such way that it is inbuilt in tooling and helps to hold the work piece in right position. Electromagnet is use to provide uniform magnetic field around the specimen by using DC supply and it also facilities cut off of magnetic flux after machining carry out Electromagnet contains number of poles which are well fitted around the specimen that keeps minimum distance from the center of flow. Machine structure contains base stand, strut and steel plates that holds whole machine in position.

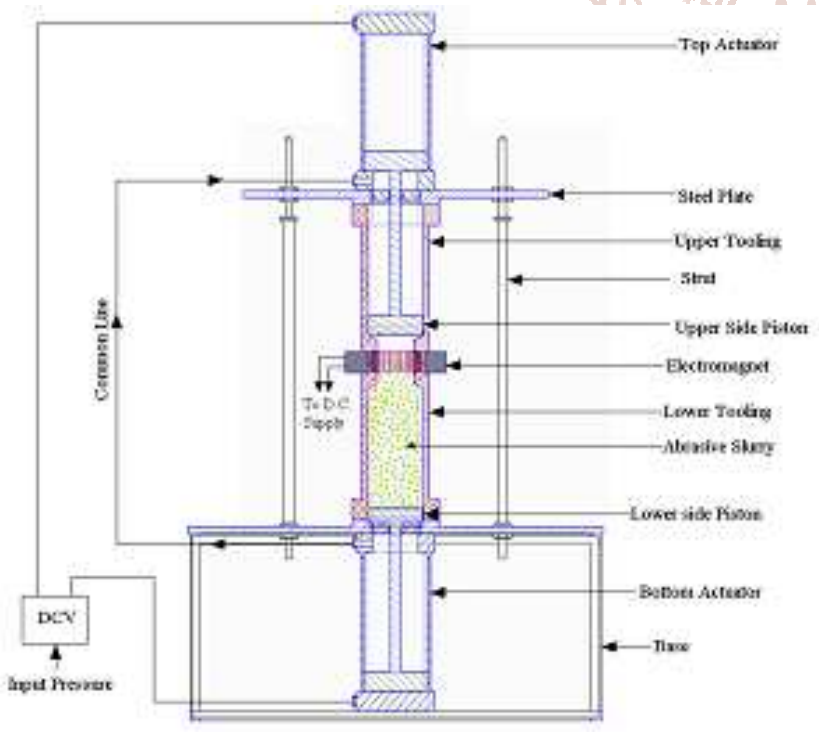

\section{A. Specimen}

The work specimen used in this test is a dog clutch contains splines (tooth) on internal surface. Dog clutch is made from alloy steel having specified dimension.

Dimension: - Do - 75mm, Di (mean) - 53.5 mm, L-26mm

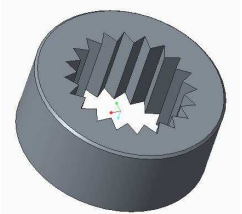

\section{B. Electromagnet}

The electromagnet was design and assembled for its location around the work piece. The electromagnet is created by manufacturing core. Core is made from number of silicon steel strip placing one on one called as stamping. Core is design in such a way that it creates number of poles around the work-piece. It consists of 24 poles that are surrounded by coils which contain 108 numbers of turns. Gauge of wire in electromagnetic coil is 28. It is positioned in such a way that it can provide the maximum magnetic field near the entire internal surface of the work piece.

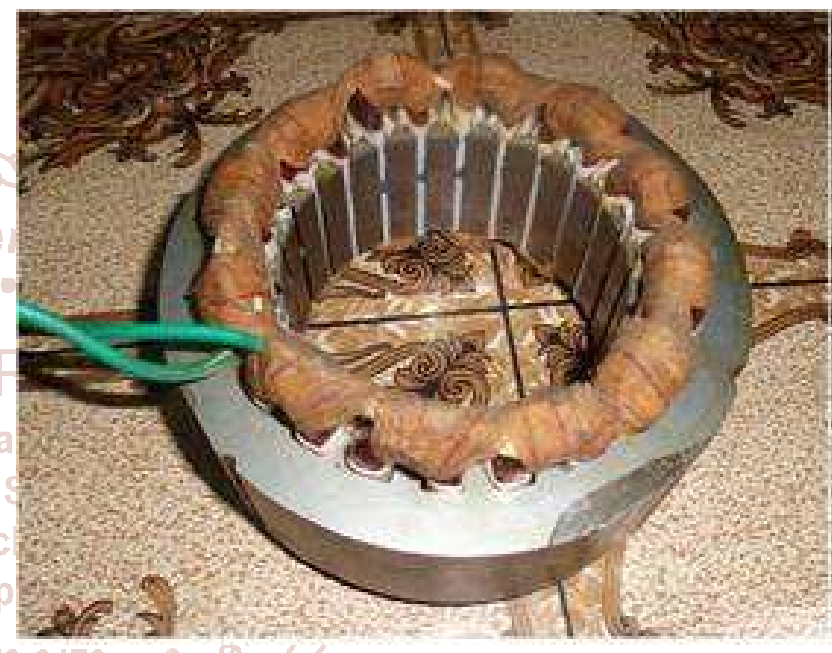

\section{Flow Media}

Flow media is in state of semi solid fluid. It is mixture abrasive such as aluminium oxide and silicon carbide followed by binding agent like oil, hydrocarbon gel, Silicon based polymer etc, which conforms the fluidity of abrasive slurry. This mixture contain $43 \%$ ( by weight) of ferromagnetic material, 42\% Al203 and 15\% Si203. In ferromagnetic materials we can use iron powder, granules of Fe etc.

\section{PROCESS PARAMETERS INDEPENDENT PARAMETERS}

\begin{tabular}{|c|c|c|c|}
\hline $\begin{array}{c}\text { Sr. } \\
\text { No }\end{array}$ & $\begin{array}{c}\text { Process } \\
\text { Parameters }\end{array}$ & Range & Unit \\
\hline 1 & Extrusion Pressure & $20-30$ & Bar \\
\hline 2 & $\begin{array}{c}\text { Abrasive carrier } \\
\text { concentration }\end{array}$ & $70-30$ & $\%$ by weight \\
\hline 3 & Viscosity of Media & 490 & Pa-s \\
\hline 4 & Media flow Rate & 618 & $\mathrm{~cm} 3 / \mathrm{min}$ \\
\hline
\end{tabular}

\section{CONSTANT PARAMETERS}

\begin{tabular}{|c|c|c|c|}
\hline $\begin{array}{c}\text { Sr. } \\
\text { No }\end{array}$ & Process Parameters & Range & Unit \\
\hline 1 & $\begin{array}{c}\text { Abrasive Particle Size } \\
\text { (mesh size) }\end{array}$ & $60-65$ & Micron \\
\hline 2 & Processing Time & 5 & Min \\
\hline 3 & Temperature of Media & $35 \pm 2$ & oC \\
\hline 4 & Initial surface roughness & 3.04 & $\mu \mathrm{m}$ \\
\hline
\end{tabular}


International Journal of Trend in Scientific Research and Development (IJTSRD) @ www.ijtsrd.com eISSN: 2456-6470

PROCESS RESPONSE

\begin{tabular}{|c|c|c|c|}
\hline $\begin{array}{c}\text { Sr. } \\
\text { No }\end{array}$ & Process Parameters & Range & Unit \\
\hline 1 & $\begin{array}{c}\text { Surface Finish } \\
\text { (improvement) }\end{array}$ & 72.72 & $\%$ \\
\hline 2 & Material Removal & 0.2 & $\begin{array}{c}\text { Gm } \\
\text { (per cycle) }\end{array}$ \\
\hline
\end{tabular}

\section{WORKING PRINCIPLE}

The abrasive slurry which is in semi solid fluid form flows through work piece. This abrasive particle is force to flow by piston cylinder by applying the pressure. Due to this, velocity of abrasive particle increases by converting potential energy into kinetic energy. When the magnetic field is applied around work piece the ferromagnetic material present in abrasive slurry get struck along with abrasive to the workpiece. Due to pressure of piston it get rubbed on surface of work-piece which results in micro-chipping causes surface finishing. This process is carried until desire surface is required. Hence by application of magnetic field the abrasive slurry sticks to the surface and increases MRR in short span of time. After desire result power supply is switched off, magnetic field is vanished hence abrasive left the surface. In this way surface finishing is done.

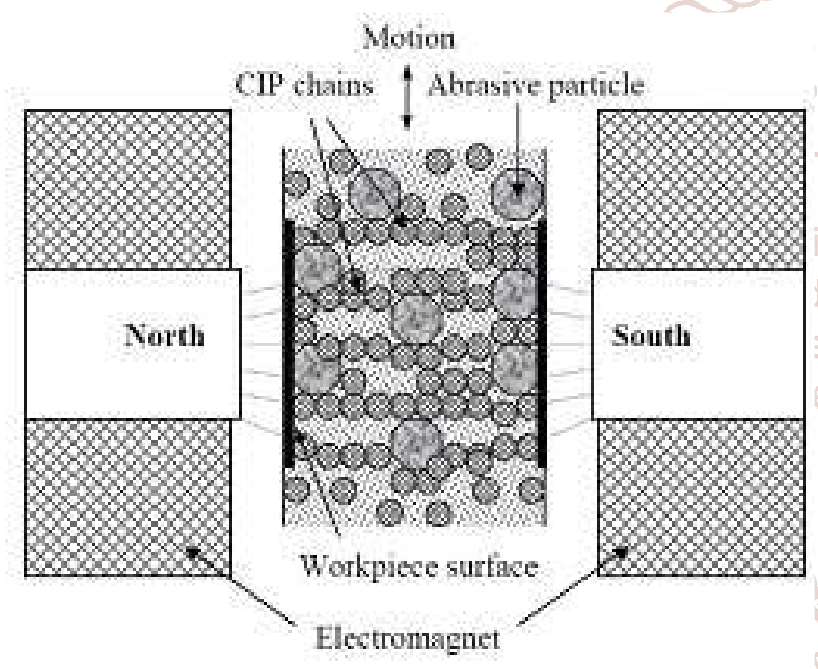

COMPARISON
\begin{tabular}{|c|c|c|}
\hline $\begin{array}{c}\text { Parameters } \\
\text { Machining Time } \\
\text { (per work piece) }\end{array}$ & $\begin{array}{c}5 \mathrm{~min} \\
\text { (for } 30 \text { Cycle) }\end{array}$ & $\begin{array}{c}\text { MAFM } \\
\text { (for } 30 \text { cycle) }\end{array}$ \\
\hline Setup Time & $2-3 \mathrm{~min}$ & $2-3 \mathrm{~min}$ \\
\hline $\begin{array}{c}\text { Surface finish } \\
\text { (Ra value in } \mu \mathrm{m} \text { ) }\end{array}$ & $0.05-1.0$ & $3.0-5.0$ \\
\hline $\begin{array}{c}\text { Material removal } \\
\text { Rate }\end{array}$ & $0.008-0.010 \mathrm{~mm}$ & $\begin{array}{c}0.020- \\
0.030 \mathrm{~mm}\end{array}$ \\
\hline Productivity & $\begin{array}{c}\text { Lower as compare } \\
\text { to MAFM }\end{array}$ & Higher \\
\hline Accuracy & Higher & Higher \\
\hline
\end{tabular}

\section{ADVANTAGES}

MAFM increases material removal rate and surface finish as compared to AFM.It effective on all material such as hard and high strength material like ceramics and carbide. It produce high degree of surface finish and accuracy and highly efficient over conventional process. Higher MRR as compare to AFM. Machining time reduce as compare to AFM and other conventional machining process.

\section{LIMITATIONS}

Abrasive material tends to get embedded if the work material is ductile. Heat generated by electromagnet may change the property of flow media. Initial cost of machine is more as compare to AFM

\section{APPLICATIONS}

A. MAFM in Automotive industry

1. Enhanced uniformity and surface quality of finished components.

2. Increased engine performance.

3. Increased flow velocity and volume.

4. Improved fuel economy and reduced emissions.

5. Extended work piece life by reducing wear and stress surfaces.

B. MAFM in Aerospace industry

1. Improved surface quality.

2. Enhanced high cycle fatigue strength.

3. Optimized combustion and hydraulics.

4. Increased airflow.

5. Extended component life.

C. MAFM in Medicine industry

1. Eliminate the surface imperfections where dangerous contaminates can reside.

2. Improved functionality, durability and reliability of medical components.

3. Enhanced uniformity and cleanliness of surfaces.

4. Extended component life.

D. MAFM in Dies and Moulds industry

1. Reduced production costs.

2. Increased production throughput.

3. i Enhanced surface uniformity, finish and cleanliness.

\section{CONCLUSION}

The magnetic field has been developed around the work piece and removes the material by friction of flow media on the work piece. This can help to reduce the manufacturing operation per cycle compared to AFM. This is a continuous process as the combination of magnetic field and flow media interacted toward the work piece and removal of material takes place. The media flow is semi viscous form, they cannot affect on work piece as it pass through it continuous motion of flow.

\section{REFERENCES}

[1] P. D. Kamble, S. P. Untawale, and S. B. Sahare Use of Magneto Abrasive Flow Machining to Increase MRR and Surface Finish, VSRD-MAP, Vol. 2 (7), 2012, 249262.

[2] Ramandeep Singh and R.S. Walia, Hybrid Magnetic Force Assistant Abrasive Flow Machining Process Study for Optimal Material Removal, International Journal of Applied Engineering Research, ISSN 09734562 Vol.7 No.11 (2012).

[3] V.K. Jain, Magnetic field assisted abrasive based micro/nano-finishing, Journal of Materials Processing Technology 209 (2009), 6022-6038.

[4] Sunil Jha and V. K. Jain, Nano-Finishing Techniques, in Prof. of Department of Mechanical Engineering at Indian Institute of Technology Kanpur - 208016,India.

[5] Sandeep Chouhan1, Sushil Mittal, International Journal of Research In Aeronautical And Mechanical Engineering, International Journal of Research In Aeronautical And Mechanical Engineering, Vol.2 Issue Jan (2014). 